\title{
Influence of Fat and Moisture Content in the Processing of Light Requeijão
}

\author{
Rita de Cássia Santos Navarro da Silva ${ }^{1}$, Valéria Paula Rodrigues Minim ${ }^{1}$, Andréa Alves Simiqueli ${ }^{1} \&$ Luis \\ Antônio Minim ${ }^{1}$ \\ ${ }^{1}$ Federal University of Viçosa, Brazil \\ Correspondence: Rita de Cássia Santos Navarro da Silva, Federal University of Viçosa, Brazil. E-mail: \\ rita.navarro@ufv.br
}

Received: July 22, 2013

Accepted: September 10, 2013 Online Published: September 23, 2013

doi:10.5539/jfr.v2n6p12

URL: http://dx.doi.org/10.5539/jfr.v2n6p12

\begin{abstract}
The objective of this study was to evaluate the influence of fat and moisture contents in the sensory characteristics and acceptance of light requeijão. The experiment followed the Central Composite Rotatable design. Formulations were characterized by Conventional Profile and the acceptability was evaluated by 100 consumers. The results were analyzed by Analysis of Variance, fitting of regression models and Preference Map. The multiple linear regression model showed the best fit for all sensorial attributes. Requeijão samples that fat reduction was coupled with increasing moisture demonstrated intermediate intensity of the sensory properties and showed the best acceptance among consumers. Such a result indicated that the reduction in fat levels should be associated to the increase in moisture of the final product so that there is equilibrium in the sensorial properties and the optimization the acceptance of the consumers.
\end{abstract}

Keywords: descriptive analysis, defatted dry extract, consumers

\section{Introduction}

Cheese processing technology initiated at the beginning of the 20th century with the need to inhibit microbial and enzymatic processes of Swiss and German cheeses in order to allow for exportation to countries with hot climates. In 1911, Geber and Steller were able to solubilize calcium paracaseinate from raw material by means of heat, utilizing sodium citrate as a fluxing agent, thus obtaining what was referred to as processed cheese. The sodium salt, under constant agitation and heat, promotes internal exchange of ions, transforming the calcium paracaseinate, of unstable hydration, in sodium paracaseinate, whose solution is colloidal and stable (Garrutti, Brito, Brandão, Uchôa \& Silva, 2003; Silva et al., 2012c).

Requeijão cremoso is a type of processed Brazilian cheese, fabricated throughout the entire Brazilian territory with some technology variations and is known for presenting an elevated fat content (Gallina, Van Dender, Yotsuyanagi, \& Rodrigues De Sá, 2008; Gomes \& Penna, 2010).The processed cheese matrix is formed of a continuous protein network, in which the fat and aqueous phases are dispersed (Udyarajan, Horne, \& Lucey, 2007). Food products with reduced fat are becoming more and more common. Consumers in general have acquired a greater understanding of the relationship between the diet and health, and are becoming more receptive to products with low levels of fat (Romeih, Michaelidou, Biliaderis \& Zerfiridis, 2002; Silva et al., 2012a). However, because fat plays an important role in the flavor, texture and appearance of foods, development of products with reduced fat but with the same sensorial quality as the conventional version is one of the large challenges faced by the food industry (Romeih et al., 2002; Drake \& Swanson, 1995; Guinee \& O'Callaghan, 2013).

The reduction of fat in requeijão cremoso promotes an increase in the percent of dry defatted extract (DDE), which favors protein-protein interactions and makes the casein matrix excessively rigid, resulting in a product with a firm texture (Metzger \& Mistry, 1995; Sheehan \& Guinee, 2004; Guinee \& O'Callaghan, 2013). Various approaches have been used to counteract the adverse effects of fat reduction of cheese. These include homogenization of cheese milk to increase the surface area of the fat phase (Poudaval \& Mistry, 1999); the addition of fat replacers to the cheese milk (Rudan, Barbano, Yun, \& Kindstedt, 1999), the addition of exopolysaccharide-producing cultures (Perry, Mcmahon, \& Oberg, 1998); and/or alterations of the production procedure to decrease the levels of DDE (Metzger, Barbano, Kindstedt, \& Guo, 2001). These methods have 
resulted in varying degrees of success.

Zalazar et al. (2002) evaluated Argentinian cream cheese with high moisture content and with the additional fat replaced with a protein (Dairy-Lo). In the results, the authors report that the cheeses with reduced fat were a desirable end product. Increasing the moisture content of the final product is presented as a simple strategy to reduce the content of defatted dry extract and restore the quality lost by reducing fat.

In this context, the objective of the present study was to evaluate the influence of the fat and moisture contents on the sensorial properties and acceptability of light requeijão.

\section{Material and Methods}

\subsection{Samples}

To define the formulations the Central Composite Rotatable Design (CCRD) was used with two factors (fat (F) and moisture $(\mathrm{M}))$ at two levels $\left(2^{2}\right)$, plus four axial points $(2 \times 2)$ and the central point. The central point was repeated three times to estimate the pure error, totaling 11 tests $(22+2 \times 2+3)$ (Figure 1).

The fat levels under study were defined so that the formulation with the greatest percentage of fat $(18.7 \%)$ met the minimal reduction $(25 \%)$ demanded by legislation to be considered as light (Brasil, 1998). The minimum fat concentration (8.7\%) and the high and low moisture concentrations $(71.0 \%$ and $64.0 \%)$ were defined by preliminary testing. The other levels of fat and moisture were stipulated by the statistical design, so that all points were encountered at a distance of $\alpha(\sqrt{2})$ from the central point $(\mathrm{CP})$.

The requeijão samples were processed using a mass obtained by direct hot acidification of milk at $70{ }^{\circ} \mathrm{C}$, in accordance with the technology described by Alves, Van Dender, Jaime, Moreno and Pereira (2007). The products were composed of mass (raw skim milk, lactic acid 85\% PA), cream (Funarbe), water, whey protein concentrate (2.0\% - WPC $34 \%$ - Gemacom), $\mathrm{NaCl}(0.80 \%$ - Cisne), emulsifying salts $(0.70 \%$ - Joha S9) and the preservatives potassium sorbate $(0.020 \%$ - Gemacom) and nisin $(0.017 \%$ - Danisco). Processing was conducted in an open pan with mechanical agitation at $50 \mathrm{rpm}$.

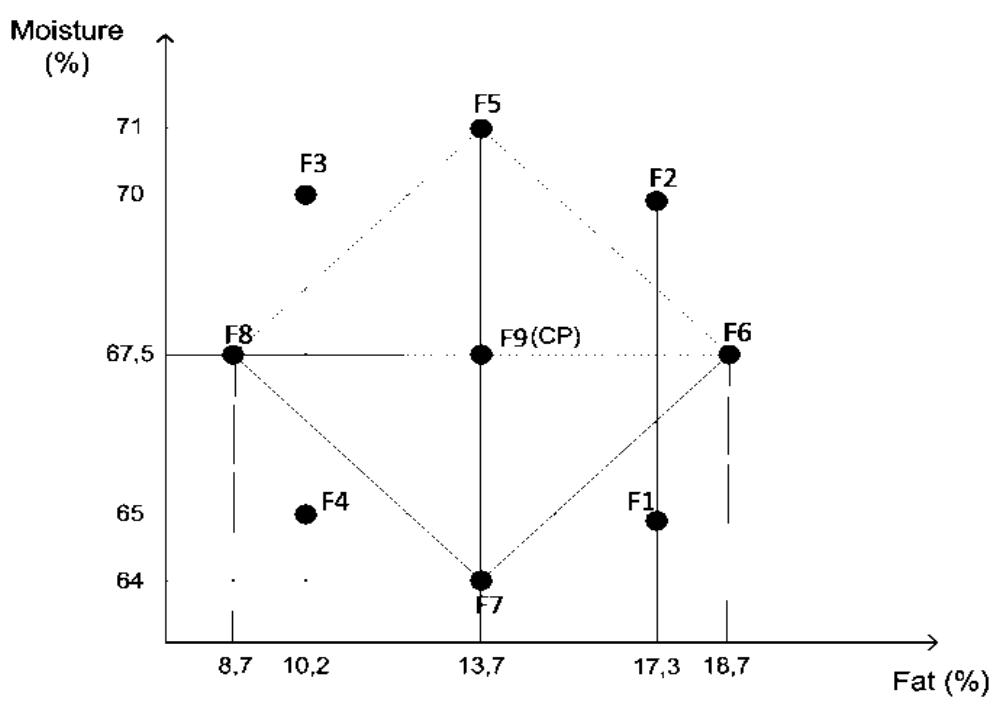

Figure 1. Disposition of the experimental points in the central composite rotatable design (CCRD)

\subsection{Centesimal Composition Analysis}

The determinations of fat, moisture, proteins and the fixed mineral residue contents of the requeijão samples were performed according to the methods described in Brasil (2005). Analyses for the determination of the centesimal composition of the requeijão samples were performed in duplicate for each repetition.

The level of carbohydrates and DDE were obtained by the indirect method, as recommended in Brasil (2005). The carbohydrate content was calculated as the percentage difference between the sum of the total content and other nutrients (\%Carbohydrate $=100 \%-[\%$ Protein $+\%$ Fat $+\%$ Fixed mineral residue $+\%$ Moisture $])$. The level of DDE was calculated as the percentage difference between the total content and the percentage of fat and 
moisture formulations (\%DDE $=\%$ Total - \%Fat - \%Moisture) .

The caloric content was calculated as a function of the composition of the requeijão samples in terms of protein, fat and carbohydrates. The conversion factors of 4,9 and $4 \mathrm{Kcal}^{-1}{ }^{-1}$ of food were used for each nutrient, respectively (United States Department of Agriculture, 1963).

To verify that the levels of fat and moisture from the processed requeijöes corresponded to the levels set by the experimental design (DCCR), a t-test for independent samples was performed to compare the theoretical value and the value obtained in practice (determining the chemical composition).

\subsection{Sensory Profile: Conventional Profile (CP)}

To characterize the sensory properties of the requeijões was utilized the Conventional Profile, described in Silva et al. (2012b, 2013).

\subsubsection{Recruitment of the Evaluator Candidates}

Fifty recruitment questionnaires were distributed to those who demonstrated an interest in participating in the sensory tests. Those recruited for pre-selection presented availability, affinity for the product under evaluation, understanding of the descriptive terms, health conditions that would not compromise the analyses and the ability to work with an unstructured scale. The ability to work with unstructured scales was evaluated by means of tests utilizing figures with different levels of filling, as proposed by Meilgaard, Civille and Carr (2006). A maximum variation of $10 \%$ from the correct value was accepted.

\subsubsection{Pre-Selection}

To evaluate the sensory discernment capacity of the candidates, a series of four global differential tests (triangular test) was applied. The criterion for selection was to assert $75 \%$ of the tests, as recommended by Meilgaard et al. (2006). The local commercial requeijão brand $\left(\mathrm{R}_{\mathrm{C}}\right)$ and requeijão diluted with $10 \%$ skim milk $\left(\mathrm{R}_{\mathrm{CD}}\right)$ were used to construct a series of differentiation tests. In preliminary tests, it was found that these products presented a significant difference $(\mathrm{p}<0.05)$ among themselves.

\subsubsection{Determination of the Descriptive Terminology and Definition of the Reference Material}

Development of the descriptive terminology was performed by fourteen pre-selected judges. The previous list technique was used to provide support to the sensory attributes acquisition, as recommended by Damásio and Costell (1991). Thus, open discussion under the supervision of a moderator was used to determine the attributes that characterized the samples, utilizing the previous list of descriptive terms for requeijão produced by Garruti et al. (2003). The judges were divided into two groups for the open session with the objective of facilitating discussion and eliciting opinions. The nine formulations were presented together with the list of descriptive terms, and the judges were asked to formulate a list of the descriptive terms that would characterize the products in relation to their appearance, aroma, flavor and texture. The attributes which characterized the requeijão samples were: characteristic color, consistency, spreadability, characteristic aroma, characteristic flavor, viscosity and adhesivity.

In a subsequent session, the judges defined each sensory term and the reference materials representing the extremes on the 9-centimeter unstructured scale (Table 1). The judges were also asked to complete an evaluation chart that contained an unstructured 9-centimeter scale associated with each sensory attribute and anchored at the extremities (weak or strong) in relation to the following attributes: characteristic color, consistency, spreadability, characteristic aroma, characteristic flavor, viscosity and adhesibility. Reference materials for the attributes of appearance (except for color) and texture were products with an instrumental firmness of $0.02 \mathrm{~N}$ (weak) and 2.34 $\mathrm{N}$ (strong). Regarding the attributes of color, aroma and flavor, formulations with combinations of fat and moisture were used, to allow for the acquisition of different sensitivity intensities of the formulations under study.

\subsubsection{Training}

Seventeen training sessions were held, which were performed in 2 months. In this stage, the judges were instructed to read the definitions of the attributes and subsequently to sample and memorize the reference materials for each sensory attribute. The method of manipulating the samples was also standardized to prevent errors in the interpretation of sensory attributes. Therefore, the judges were clearly exposed to the sensory stimulus for each attribute, clarifying "what" and "how" the sensory stimulus should be evaluated. During the training sessions, seven practical sessions were also held in which panelists were asked to rate the requeijão samples using an unstructured 9-centimeter scale. Training was terminated when the judges determined there were no difficulties in evaluating the samples. 
Table 1. Sensory attributes determined by the panel of evaluators; their respective definitions and standards define the extremes on the non-structured scale

\begin{tabular}{|c|c|c|}
\hline ATTRIBUTES & DEFINITIONS & REFERENCE MATERIALS \\
\hline \multicolumn{3}{|l|}{ APPEARANCE } \\
\hline Characteristic color & $\begin{array}{l}\text { Color of, varying from whitish-yellow } \\
\text { to clear yellow. }\end{array}$ & $\begin{array}{l}\text { Weak: cheesecurd containing } 17.3 \% \mathrm{~F} \text { and } 70 \% \mathrm{M} \\
\text { Strong:cheesecurd containing } 18.7 \% \mathrm{~F} \text { and } 67.5 \% \mathrm{M}\end{array}$ \\
\hline Consistency & $\begin{array}{l}\text { Force necessary to spread the product } \\
\text { with a spoon. }\end{array}$ & $\begin{array}{l}\text { Weak: cheesecurd containing } 17.3 \% \mathrm{~F} \text { and } 70 \% \mathrm{M} \\
\text { Strong:cheesecurd containing } 8.7 \% \mathrm{~F} \text { and } 67.5 \% \mathrm{M}\end{array}$ \\
\hline Spreadability & $\begin{array}{l}\text { Ability to spread the cheesecurd on a } \\
\text { cracker with a spoon. }\end{array}$ & $\begin{array}{l}\text { Weak: cheesecurd containing } 8.7 \% \mathrm{~F} \text { and } 67.5 \% \mathrm{M} \\
\text { Strong:cheesecurd containing } 17.3 \% \mathrm{~F} \text { and } 65 \% \mathrm{M}\end{array}$ \\
\hline \multicolumn{3}{|l|}{ AROMA } \\
\hline $\begin{array}{l}\text { Characteristic } \\
\text { aroma }\end{array}$ & Aroma of cheesecurd. & $\begin{array}{l}\text { Weak:cheesecurd containing } 8.7 \% \mathrm{~F} \text { and } 67.5 \% \mathrm{M} \\
\text { Strong:cheesecurd containing } 18.7 \% \mathrm{~F} \text { and } 67.5 \% \mathrm{M}\end{array}$ \\
\hline \multicolumn{3}{|l|}{ FLAVOR } \\
\hline Characteristicflavor & Flavor of cheesecurd. & $\begin{array}{l}\text { Weak:cheesecurd containing } 8.7 \% \mathrm{~F} \text { and } 67.5 \% \mathrm{M} \\
\text { Strong:cheesecurd containing } 18.7 \% \mathrm{~F} \text { and } 67.5 \% \mathrm{M}\end{array}$ \\
\hline \multicolumn{3}{|l|}{ TEXTURE } \\
\hline Viscosity & $\begin{array}{l}\text { Force necessary to pull the product } \\
\text { from a spoon to the mouth. }\end{array}$ & $\begin{array}{l}\text { Weak: cheesecurd containing } 17.3 \% \mathrm{~F} \text { and } 70 \% \mathrm{M} \\
\text { Strong:cheesecurd containing } 8.7 \% \mathrm{~F} \text { and } 67.5 \% \mathrm{M}\end{array}$ \\
\hline Adhesivity & $\begin{array}{l}\text { Force necessary to remove the product } \\
\text { which adheres to the palate. }\end{array}$ & $\begin{array}{l}\text { Weak: cheesecurd containing } 17.3 \% \mathrm{~F} \text { and } 70 \% \mathrm{M} \\
\text { Strong:cheesecurd containing } 8.7 \% \mathrm{~F} \text { and } 67.5 \% \mathrm{M}\end{array}$ \\
\hline
\end{tabular}

F: fat content; M: moisture content.

\subsubsection{Evaluation of Performance of the Judges}

A preliminary test was performed to verify that the judges were adequately trained. For this purpose, the final evaluation test of the products was simulated, utilizing the evaluation form containing all attributes and the unstructured 9-centimeter scale. The requeijões F2 $(17.3 \% \mathrm{~F}$ and $70.0 \% \mathrm{M})$ and $\mathrm{F} 4(10.2 \% \mathrm{~F}$ and $65.0 \% \mathrm{M})$, encoded with three randomized digits, were presented to the judges according to the Balanced Block Design (BBD) design with four repetitions, with each judge considered as a block. Samples were presented to the judges at the same time, in each repetition. The products were evaluated at a temperature of $7 \pm 1^{\circ} \mathrm{C}$.

To evaluate the discriminatory potential and reproducibility of the results, analyses of variance (ANOVA) were performed with two sources of variation (sample and repetition) per attribute for each judge. The judges that presented a maximal probability of $30 \%$ for $\mathrm{F}_{\text {SAMPLE }}\left(\mathrm{F}_{\mathrm{SAMPLE}}<0.30\right)$ and a minimal probability of $5 \%$ for $\mathrm{F}_{\text {REPETITION }}\left(\mathrm{F}_{\text {REPETITION }}>0.05\right)$ for all attributes were selected for the final stage of the CP. The selection parameters $\left(\mathrm{F}_{\text {SAMPLE }}\right.$ and $\left.\mathrm{F}_{\text {REPETITION }}\right)$ utilized were more rigorous than those proposed by Damásio and Costell (1991). To evaluate the agreement of a judge with the team, the average individual score was compared with the average score of the team, as performed by Richter, Almeida, Prudencio and Benassi (2010). Of the fourteen judges, nine were selected to make up the sensorial team by presenting satisfactory selection parameters.

\subsubsection{Final Evaluation of the Products}

The samples encoded with three random digits were randomly presented to the nine judges selected utilizing the Balanced Block Design (BBD) design; i.e., each judge evaluated all formulations. Repetitions of the central point were used to estimate the pure error. The samples were served at $7 \pm 1{ }^{\circ} \mathrm{C}$, and the judges received the evaluation form containing all sensory attributes and the nine centimeter scale (serial protocol), as well as the list of definitions of the sensory attributes.

The effect of fat and moisture contents on the sensory properties of the requeijões was analyzed by analysis of variance (F test), Principal Component Analysis (PCA) and adjusted regression models. The analysis of variance 
with two sources of variation (sample and judge) and the interaction of sample*judge was performed for each attribute separately. To select the best model fit to the data, we assessed the following parameters: no significant lack of fit $(p>0.10)$, significance of regression coefficients $(p<0.10)$ and, finally, the explanation of model by the coefficient of determination $\mathrm{R}^{2}$.

\subsection{Sensorial Acceptability}

On the campus of the Universidade Federal de Viçosa, 100 consumers of requeijão were recruited. The requeijão formulations were served to the consumers both randomly and monadically, in disposable cups containing approximately $10 \mathrm{~g}$ of the product. A nine point hedonic scale was used, varying from "extremely liked" (score 9) to "extremely disliked" (score 1) so that the panelists could express acceptance in relation to texture of the products (Meilgaard et al., 2006).

The results of acceptance were analyzed by the Internal Preference Map, where the data acceptance tests (consumer) were organized in a matrix of samples (in rows) and consumers (in columns), and were subject to Principal Components Analysis (PCA), as described in Minim (2010). In addition, Response Surface Analysis (RSA) was used to verify the behavior depending on the sensory acceptance of fat and moisture contents.

\subsection{Statistical Analyses}

Statistical analyses were performed in SAS (Statistical Analysis System), licensed for use at Universidade Federal de Viçosa in 2013.

\subsection{Ethics Committee}

This project was analyzed and approved by the Scientific Committee of the Postgraduate Department of Food Technology, Federal University of Viçosa, process ${ }^{\circ} 50717258524 / 2009$, obeying, as outlined, the necessary requirements for its publication.

\section{Results and Discussion}

\subsection{Centesimal Composition of the Light Requeijão Samples}

The obtained values of fat and moisture contents of the processed requeijão cheeses are shown in Table 2. Theoretical and experimental levels of fat and moisture in the requeijão samples did not differ significantly by the t-test, and presented p-values of 0.8670 and 0.7887 , respectively. This result indicates that the processed formulations met the requirements stipulated by the design.

Table 2. Centesimal composition of the light requeijão samples with the addition of WPC

\begin{tabular}{|c|c|c|c|c|c|c|c|}
\hline \multirow{2}{*}{ Formulations } & \multicolumn{5}{|c|}{ CONSTITUENTS (\%) } & \multirow{2}{*}{$\begin{array}{l}\text { DDE } \\
(\%)\end{array}$} & \multirow{2}{*}{$\begin{array}{c}\text { CaloricValue } \\
\text { (Kcal) }\end{array}$} \\
\hline & Moisture & Fat & Protein & Residue Mineral Fixed & Carbohydrate & & \\
\hline F1 & $64.90 \pm 0.10$ & $16.50 \pm 0.20$ & $14.02 \pm 0.25$ & $3.14 \pm 0.09$ & $1.44 \pm 0.14$ & $18.60 \pm 0.30$ & 210.34 \\
\hline $\mathbf{F} 2$ & $69.75 \pm 0.10$ & $16.40 \pm 0.10$ & $10.01 \pm 0.20$ & $2.69 \pm 0.18$ & $1.15 \pm 0.02$ & $13.85 \pm 0.00$ & 192.24 \\
\hline F3 & $69.75 \pm 0.10$ & $10.50 \pm 0.13$ & $14.35 \pm 0.25$ & $3.28 \pm 0.46$ & $2.12 \pm 0.68$ & $19.75 \pm 0.03$ & 165.02 \\
\hline F4 & $65.47 \pm 0.10$ & $11.50 \pm 0.32$ & $18.14 \pm 0.04$ & $3.19 \pm 0.11$ & $1.70 \pm 0.28$ & $23.03 \pm 0.22$ & 182.86 \\
\hline F5 & $71.02 \pm 0.10$ & $13.00 \pm 0.18$ & $12.07 \pm 0.30$ & $2.65 \pm 0.01$ & $1.26 \pm 0.01$ & $15.98 \pm 0.28$ & 170.32 \\
\hline F6 & $67.20 \pm 0.00$ & $18.50 \pm 0.53$ & $10.54 \pm 0.09$ & $2.51 \pm 0.02$ & $1.26 \pm 0.45$ & $14.31 \pm 0.52$ & 213.7 \\
\hline F7 & $63.50 \pm 0.10$ & $13.10 \pm 0.08$ & $18.46 \pm 0.25$ & $2.96 \pm 0.01$ & $1.98 \pm 0.06$ & $23.40 \pm 0.18$ & 199.66 \\
\hline F8 & $66.67 \pm 0.05$ & $8.45 \pm 0.13$ & $19.40 \pm 0.17$ & $3.40 \pm 0.29$ & $2.08 \pm 0.28$ & $24.88 \pm 0.18$ & 161.97 \\
\hline F9 R1 (CP) & $67.15 \pm 0.00$ & $13.60 \pm 0.15$ & $15.09 \pm 0.20$ & $2.80 \pm 0.00$ & $1.37 \pm 0.05$ & $19.26 \pm 0.15$ & 188.24 \\
\hline F9 R2 (CP) & $67.02 \pm 0.10$ & $13.75 \pm 0.20$ & $15.01 \pm 0.05$ & $2.88 \pm 0.07$ & $1.34 \pm 0.28$ & $19.23 \pm 0.30$ & 189.15 \\
\hline F9 R3 (CP) & $67.23 \pm 0.24$ & $13.20 \pm 0.18$ & $15.49 \pm 0.24$ & $2.79 \pm 0.08$ & $1.29 \pm 0.20$ & $19.57 \pm 0.26$ & 185.92 \\
\hline
\end{tabular}

F1: $17.3 \% \mathrm{~F}$ e $65 \% \mathrm{M}$; F2: $17.3 \% \mathrm{~F}$ e $70 \% \mathrm{M}$; F3: $10.2 \% \mathrm{~F}$ e $70 \% \mathrm{M}$; F4: $10.2 \% \mathrm{~F}$ e $65 \% \mathrm{M}$; F5: $13.7 \% \mathrm{~F}$ e $71 \% \mathrm{M}$; F6: $18.7 \% \mathrm{~F}$ e $67.5 \% \mathrm{M}$; F7: $13.7 \% \mathrm{~F}$ e $64 \% \mathrm{M} ; \mathbf{F 8}$ : $8.7 \% \mathrm{~F}$ e $67.5 \% \mathrm{M}$; F9 (central point): $13.7 \% \mathrm{~F}$ e 67.5\%M. \%DDE (DeffatedDryExtract): 100 - \%Fat - \%Moisture. Standard deviation calculated according to the replicates. 
The different combinations of fat and moisture produced requeijão samples with different defatted dry extracts (DDE), due to the fact that this constituent (DDE) is calculated by the percent difference between the total content and levels of fat and moisture. Therefore, the reduction in fat and moisture contents resulted in an increase in protein levels (casein) of the requeijão samples. Similar results were encountered by Soares et al. (2002) and by Cunha, Viotto and Viotto (2006) when determining the centesimal composition of low fat cheeses.

Thus, requeijão samples F2 and F3 presented an increase of $13.85 \%$ to $19.76 \%$ in DDE when the fat level was reduced from $16.4 \%$ to $10.5 \%$. The same behavior was verified for samples F6, F9 and F8 (approximately $67.5 \%$ moisture) and also for formulations F1 and F4 (65\% M).The moisture content also caused changes in the DDE of the requeijão. When comparing the formulations within the same level of fat reduction, it was found that the DDE in formulations F1 and F2 increased from $13.85 \%$ to $18.06 \%$ when the content moisture decreased from $69.75 \%$ to $64.90 \%$. The same was observed for formulations F5, F7 and F9 $(13.7 \% \mathrm{~F})$ and for F3 and F4 $(10.2 \%$ F).

Therefore, it was identified that the levels of fat and moisture inversely influenced the percentage of DDE in the requeijão samples, being that products with different combinations of fat and water (F1, F3 and F9) presented similar DDE levels (approximately 19.30\%) due to compensation of water in the DDE content generated by the reduction in fat.

Formulations in which fat reduction did not accompany the increase in water content (F4, F7 and F8) presented elevated protein contents (approximately $23.8 \%$ DDE). However the requeijão samples containing greater percentages of fat and also presented elevated water contents (F2, F5 and F6) presented low DDE levels (approximately $14.70 \%$ ).

In regards to the caloric value, samples with less fat and greater water concentrations (F3) presented less energy than the other formulations, which is very interesting for industry since this product can be produced for less money (less utilization of cream and mass) and provides a low caloric content. It also presents the marketing appeal that this requeijão has a $65 \%$ reduction in fat content of the traditional product (approximately $25 \% \mathrm{~F}$ ).

\subsection{Sensory Characterization of Light requeijão: Conventional Profile}

Nine panelists were selected to make up a sensorial team, who presented the ability of discrimination and repeatability of results, as recommended by Damásio and Costell (1991). The seven attributes evaluated showed to have significant effect $(p<0.001)$ on the sample*panelist interaction. Therefore, the test for the effect of the samples was performed again, using the mean square of interaction as the denominator for all sensorial attributes. The requeijão samples differed among themselves $(\mathrm{p}<0.001)$ by the $\mathrm{F}$ test (versus interaction) in all attributes evaluated.

In the Principal Component Analysis (PCA), Figure 2, the first principal component explained $91.96 \%$ of data variation, being sufficient to discriminate the formulations in regards to their sensorial attributes, however only one dimension was considered. The spatial separation of the nine formulations suggests the formation of three distinct groups: the first group formed by samples F4, F7 and F8, the second group composed of formulations F1, F3 and F9, and the other consisting of formulations F2, F5 and F6.

In Figure 2, the sensorial attributes are represented by vectors. Each abscissa and ordinate of a vector is, respectively, a linear correlation between a sensorial attribute and the first and second principal component, respectively. All attributes, except for color, presented correlation $(p<0.10)$ with the first principal component. The color attribute is correlated with only the second principal component, presenting little importance for sensorial characterization of the requeijão samples since the second principal component explained only $5.55 \%$ of the variation of data. The attribute "characteristic color" showed little importance for sensory description of requeijão samples, probability because the samples presented a little difference in color. Therefore, it was not sought to adjust the regression models for the attribute of color. 


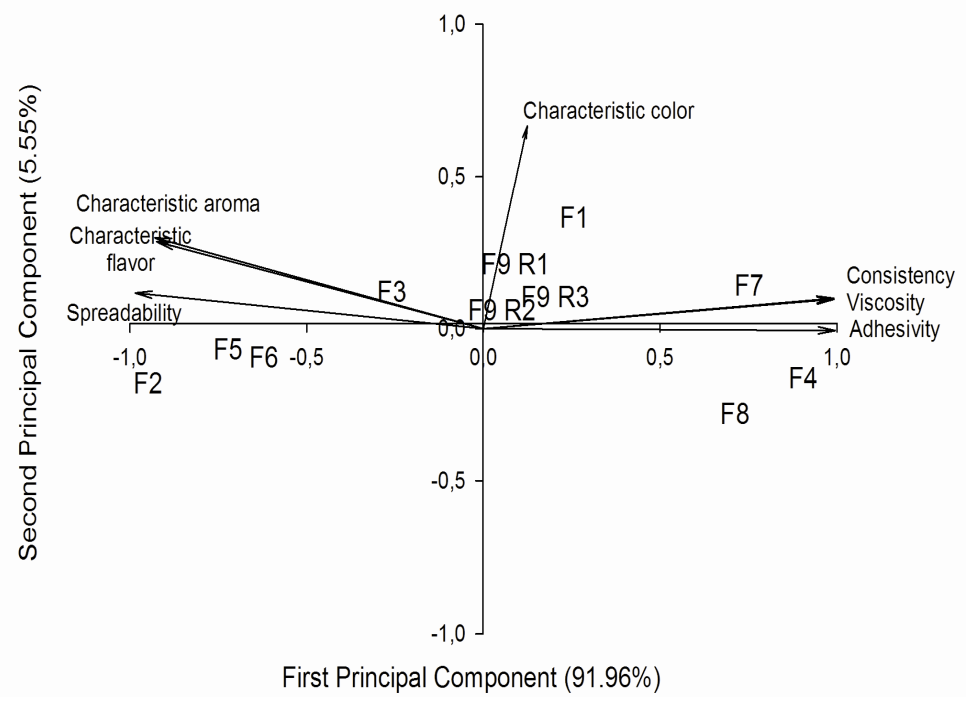

Figure 2. Graphical representation of the sensorial descriptors and the requeijão samples in relation to the two principal components

The formulations F4, F7 and F8 showed a greater intensity of the attributes of consistency, viscosity and adhesivity. The requeijoes F2, F5 and F6 were characterized by the attributes of characteristic aroma, characteristic flavor and spreadability. The group represented by the formulations F1, F3 and F9 showed an intermediate intensity of sensory attributes.

The influence of fat and moisture content on the sensorial attributes was modeled statistically by means of the equations presented in Table 3. The models were tested in regards to the lack of fit and significance of the regression parameters, and also presented a precision coefficient greater than $85 \%$. Effects of second degree and interaction were not significant $(\mathrm{p}>0.10)$ by the t-test.

The levels of fat and moisture positively contributed to the intensity of the attributes of aroma, flavor and spreadability, and negatively for the attributes of consistency, viscosity and adhesivity.

The relation of fat content with the attributes of color and flavor is due to the presence of liposoluble pigments, especially carotenoids present in the fat of the milk, which are responsible for the aroma and flavor of lactic products (Fox \& Mcsweeney, 1998). With regards to moisture content, the relationship with the flavor attribute is due to the greater contact surface of the requeijão with the increased moisture content (less consistent), which provokes better spreadability of the product on the palate and allows for better perception of the flavor attributes. However for the aroma attribute, such a result is due to the greater volatilization of aromas in more aqueous foods (Deibler \& Delwiche, 2004). In the PCA (Figure 2), the requeijão samples with greatest fat contents, combined with elevate moisture contents (F2, F5 and F6), presented greater intensity of the aroma and flavor attributes, indicating that there is an inverse relation between these constituents (fat and moisture) and the attributes of aroma and flavor.

Considering the attributes of consistency, viscosity and adhesivity, the constituents under study (fat and moisture) presented a negative effect on the intensity of these attributes (Table 3). This is due to the relation of fat and moisture content with the protein content (DDE) of the requeijão samples, where formulations with greater levels of fat and moisture showed dilution of DDE causing losses in consistency, viscosity and adhesivity. This behavior was observed in the PCA, Figure 2, where the formulations with elevated fat and moisture contents (F2, F5 and F6) showed lower intensity of these attributes. This relationship is due to the low DDE conferred by high levels of the factors under study (fat and moisture); there are fewer forces, inter- and intra-molecular, associated with casein (Dimitreli \& Thomareis, 2004). An inverse behavior was verified for the formulations with greater levels of defatted dry extract (F4, F7 and F8), Figure 2, which was characterized by presenting a greater intensity of the consistency, viscosity and adhesivity attributes than the other formulations. The elevated DDE level provoked the enrichment of the protein matrix due to the elevated number of protein-protein interactions, 
causing an increase in the intensity of these texture attributes (Fox, Guinee, Cogan, \& Mcsweeney, 2000).

The spreadability attribute showed a positive correlation with fat and moisture contents in regards to its intensity, due to this attribute possessing an inverse relation with the attributes of consistency and viscosity, since the more viscous sample possessed an inferior ability to be spread on a cracker (Garruti et al., 2003). Thus, requeijão samples with low levels of DDE (F2, F5 and F6) present greater spreadability. For the formulations with greater DDE percentages (F4, F7 and F8), i.e., lower content of fat and moisture, the opposite behavior was verified.

The formulations with intermediate levels of DDE (F1, F3 and F9) showed intermediately intensities of the sensorial attributes, indicating that the combinations of fat and moisture of these requeijão samples permitted the occurrence of an equilibrium in DDE, and consequently, in the texture and flavor of the requeijão.

Table 3. Statistical model of the effect of fat and moisture on the sensory properties of light requeijão supplemented with WPC

\begin{tabular}{ll}
\hline Models & $\mathbf{R}^{2}$ \\
\hline$Y_{\text {AROMA }}=-37.5274+0.3760_{F A T}+0.5433_{\text {MOISTURE }}$ & 0.8537 \\
$Y_{\text {CONSISTENCY }}=65.0761-0.4254_{F A T}-0.8070_{\text {MOISTURE }}$ & 0.9399 \\
$Y_{\text {SPREADABILITY }}=-56.0184+0.5199_{F A T}+0.7898_{\text {MOISTURE }}$ & 0.9068 \\
$Y_{\text {FLAVOR }}=-38.6437+0.3606_{F A T}+0.5650_{\text {MOISTURE }}$ & 0.8547 \\
$Y_{\text {VISCOSITY }}=67.5738-0.4437_{F A T}-0.8423_{\text {MOISTURE }}$ & 0.9496 \\
$Y_{\text {ADHESIVITY }}=65.5538-0.5192_{F A T}+0.8441_{\text {MOISTURE }}$ & 0.9424 \\
\hline
\end{tabular}

Y: response variable; $\bar{F}$ : fat content; $\mathrm{M}$ : moisture content; $\mathrm{R}^{2}$ : coefficient of determination.

\subsection{Sensorial Acceptance}

In the Internal Preference Map (Figure 3), the first principal component explained $50.67 \%$ and the second $21.83 \%$, thus totaling $72.50 \%$ of the variance between the nine requeijão formulations in regards to acceptance related to overall impression.

The spatial separation of the requeijão samples suggests the formation of four distinct groups in accordance with sensorial acceptance, where one group was formed by requeijão samples F1, F3 and F9 (first quadrant), another formed by formulations F4, F7 and F8 (second quadrant), a third group composed of the requeijão F2 (third quadrant) and the last group formed by the formulations F5 and F6.

The consumers are represented by points where each abscissa and ordinate of a point is, respectively, the linear correlation between the consumer and the principal components. The correlation of the consumers by at least one of the components indicates a difference in the acceptance of the formulations. Therefore, the consumers located in the central region of the graph are not correlated to either of the two components, and therefore do not discriminate the requeijão samples in regards to acceptance. As can be observed in Figure 3, few consumers were located in the central region, indicating that the different requeijão samples differed well in regards to acceptance.

In this type of graphical representation, the consumers are located near to the products they liked. Thus, formulations F1, F3 and F9 presented a greater acceptance since the majority of consumers are located near these formulations. The requiejão samples F5 and F6 were also accepted, however by a smaller group of consumers; the formulations F2, F4, F7 and F8 (situated in the second and third quadrant) were not accepted by the consumers.

The sensorial dislike of requeijão formulations F4, F7 and F8 may be explained due to the elevated DDE level (approximately $24.80 \%$ ) of these products, which present a very strong protein matrix, not favoring the texture of the samples. However for the requeijão F2 the opposite was verified, where the increase in moisture content to $70 \%$ combined with $17.3 \%$ fat resulted in a high dissolution of the DDE $(13.80 \%)$, producing in a very flaccid requeijão which also caused for a poor acceptance of the product. 


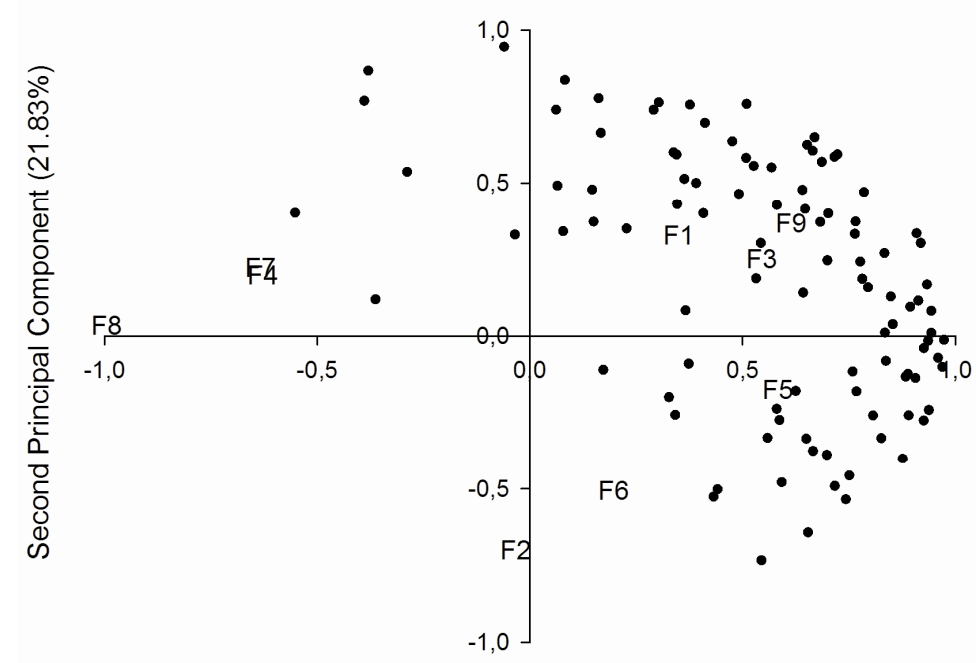

First Principal Component (50.67\%)

Figure 3. Graphical representation of the requeijão formulations and of the consumers in relation to the two principal components in regards to overall impression

It was verified that the requeijão samples F1, F3 and F9, formulations with different levels of fat, showed similar sensorial acceptance when combined with different moisture contents, i.e., the requeijão with $17.3 \%$ fat and $65 \%$ moisture (F1) presented sensorial acceptability equivalent to the product with $10.2 \%$ fat and $70 \%$ moisture (F3), and also equivalent to that with $13.7 \%$ fat and $67.5 \%$ moisture (F9). It should be emphasized that these formulations presented similar DDE values (approximately 19.30\%), indicating that the reduction in requeijão fat levels is linked to the increase in moisture content so that there is equilibrium in the sensorial characteristics of the product.

The relationship between the DDE level and sensorial acceptance may be easily visualized in Figure 4, which is a graphical representation of the surface response of sensorial acceptance in function of the fat and moisture levels, where it can be observed that as the level of fat in the requeijão decreases, greater should be the moisture content of the product so that the sensorial properties are pleasant to the consumers. From this information, it is possible to determine diverse combinations of fat and moisture, within the studied concentrations, which meet the expectations of consumers.

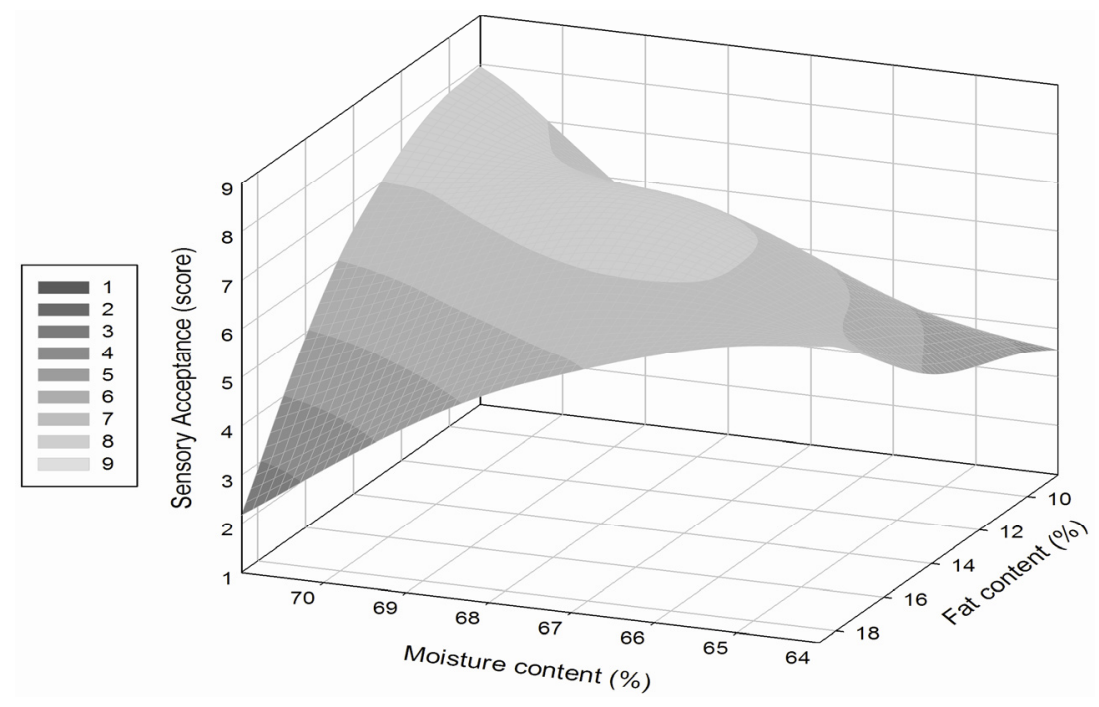

Figure 4. Graphical representation of the Surface Response Analysis for acceptance in the function of fat and moisture content of the requeijão 


\section{Conclusion}

The levels of fat and moisture are presented as determining factors sensorial quality in light requeijão, indicating the relevance of this study. Different combinations of fat and moisture resulted in requeijão samples with similar sensorial profiles, showing that the reduction in fat concentration in requeijão should be aligned with increase in moisture content of the final product so that there is an equilibrium in the defatted dry extract (DDE), and consequently in the sensorial quality of the product.

The surface response analysis allowed for identification of innumerous combinations of fat and moisture which meet the expectations of the consumers in regards to sensorial quality of the requeija a samples, allowing the development of products with different levels of fat reduction and similar sensorial acceptance.

The conclusions obtained from this research about the influence of the reduction of fat and moisture in the sensory characteristics of requeijão are valid only for the concentration ranges studied. The reduction of fat in the requeija a must be associated with the increase in moisture of the final product so that it shows a balance in DDE, also generating a balance in the texture of the product and providing improvement in sensory acceptability. However, it is not known what effect on product texture and sensory acceptability for reductions in fat content below $8.7 \%$. The mathematical model established in this study can be used to predict the sensory characteristics of requeijão, from fat and moisture content of the product to the concentration range evaluated, which was from 8.7 to $18.7 \%$ (fat) and from 64 to $71 \%$ (moisture).

\section{Acknowledgements}

The authors would like to acknowledge the Conselho Nacional de Pesquisa e Desenvolvimento (CNPq) and Fundação de Amparo à Pesquisa de Minas Gerais (Fapemig) for their financial support.

\section{References}

Alves, R. M. V., Van Dender, A. G. F., Jaime, S. B. M., Moreno, I., \& Pereira, B. C. (2007). Effect of light and packages on stability of spreadable processed cheese. International Dairy Journal, 17, 365-373. http://dx.doi.org/10.1016/j.idairyj.2006.04.004

Brasil. (1998). Vigilância Sanitária, Ministério da Saúde (ANVISA). Portaria no 27, de 13 de Janeiro de 1998. Regulamento Técnicode Informação nutricional complementar. Diário Oficial da União, Brasília, DF.

Brasil. Instituto Adolfo Lutz. Métodos Físico-Químicos para Análise de Alimentos. Brasília. IV Edição, (2005). p. 1018.

Cunha, C. R., Viotto, W. H., \& Viotto, L. A. (2006). Use of low concentration factor ultrafiltration retentates in reduced fat "Minas Frescal" cheese manufacture: Effect on composition, proteolysis, viscoelastic properties

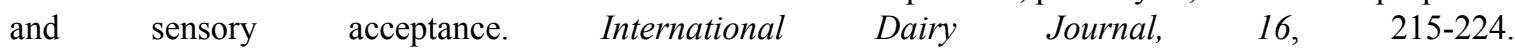
http://dx.doi.org/10.1016/j.idairyj.2005.03.004

Damásio, M. H., \& Costell, E. (1991). Análisis sensorial descriptivo: generación de descriptores y selección de catadores. Revista Agroquímica Tecnológica de Alimentos, 31, 165-178.

Deibler, K. D., \& Delwiche, J. (2004). Handbook of flavorcharacterization: sensoryanalysis, chemistry and physiology. New York: Inc: Marcel Dekker.

Dimitreli, G., \& Thomareis, A. S. (2004). Effect of temperature and chemical composition on processed cheese apparent viscosity. Journal of Food Engineering, 64, 265-271. http://dx.doi.org/10.1016/j.jfoodeng.2003.10.008

Drake, M. A., \& Swanson, B. G. (1995). Reduced and low fat cheese technology: a review. Trends Food Science and Technology, 6, 336-369. http://dx.doi.org/10.1016/j.foodeng.2003.10.008

Fox, P. F., Guinee, T. P., Cogan, T. M., Mcsweeney, P. L. H. (2000). Cheese Rheology and Texture: Fundamentals of Cheese Science (p. 638). Gaithersburg, Maryland: Aspen Publishers, Inc.

Fox, P. F., \& Mcsweeney, P. L. H. (1998). Dairy Chemistry and Biochemistry; London, Weinheim, New York, Tokyo, Melbourne, Madras: Blackie Academic \& Professional, p. 463.

Gallina, D. A., Van Dender, A. G. F., Yotsuyanagi, K., \& Rodrigues de Sá, P. B. Z. (2008). Influence of storage temperature on the texture profile and color characteristics of UHT Requeijão cremoso. Brazilian Journal of Food Technology, 11(3), 169-174.

Garrutti, D. S., Brito, E. S., Brandão, T. M., Uchôa Jr, P., \& Silva, M. A. A. P. (2003). Desenvolvimento do perfil sensorial e aceitação de requeijão cremoso. Ciência e Tecnologia de Alimentos, 23(3). 
http://dx.doi.org/10.1590/S0101-20612003000300024

Gomes, R. G. \& Penna, A. L. B. (2010). Caracterização de requeijão cremoso potencialmente prebiótico pela adição de inulina e proteína de soja. Boletim do Centro de Pesquisa de Processamento de Alimentos, 28(2), 289-302.

Guinee, T. P., \& O'Callaghan, D. J. (2013). Effect of increasing the protein-to-fat ratio and reducing fat content on the chemical and physical properties of processed cheese product. Journal of Dairy Science. http://dx.doi.org/10.3168/jds.2013-6685

Meilgaard, M. C., Civille, G. V. \& Carr, B.T. (2006). Sensory Evaluation Techniques (4th ed.) Boca Raton: CRC Press.

Metzger, L. E., Barbano, D. M., Kindstedt, P. S., \& Guo, M. R. (2001). Effect of milk preacidification on low fat Mozzarella cheese: 11. Chemical and functional properties during storage. Journal of Dairy Science, 84, 1348-1356. http://dx.doi.org/10.3168/jds.S0022-0302(01)70165-8

Metzger, L. E., \& Mistry, V. V. (1995). A new approach using homogenization of cream in the manufacture of reduced fat cheddar cheese. Journal of Dairy Science, 78, 1883-1895. http://dx.doi.org/10.3168/jds.S0022-0302(95)76813-8

Minim, V. P. R. (2010). Análise Sensorial - Estudo com Consumidores (2nd ed.). Viçosa, M.G: Editora da Universidade Federal de Viçosa.

Perry, D. B., Mcmahon, D. J., \& Oberg, C. J. (1998). Manufacture of low fat Mozzarella cheese using exopolysaccharide-producing starter cultures. Journal of Dairy Science, 81, 563-566. http://dx.doi.org/10.3168/jds.S0022-0302(98)75608-5

Poudaval, V. S., \& Mistry, V. V. (1999). Manufacture of reduced-fat Mozzarella cheese using ultrafiltered sweet buttermilk and homogenized cream. Journal of Dairy Science, 82, 1-9. http://dx.doi.org/10.3168/jds.S0022-0302(99)75202-1

Richter, V. B., Almeida, T. C. A., Prudencio, S. H., \& Benassi, M. T. (2010). Proposing a ranking descriptive sensory method.Food Quality and Preference, 21, 611-620. http://dx.doi.org/10.1016/j.foodqual.2010.03.011

Romeih E.A., Michaelidou, A., Biliaderis, C. G., \& Zerfiridis, G. K. (2002).Low-fat white-brined cheese made from bovine milk and two commercial fat mimetics: chemical, physical and sensory attributes. International Dairy Journal, 12, 525-540. http://dx.doi.org/10.1016/S0958-6946(02)00043-2

Rudan, M. A., Barbano, D. M., Yun, J. J., \& Kindstedt, P. S. (1999). Effect of fat reduction on chemical composition, proteolysis, functionality, and yield of Mozzarella cheese. Journal of Dairy Science, 82, 661-672. http://dx.doi.org/10.3168/jds.S0022-0302(99)75282-3

Sheehan, J. J., \& Guinee, T. P. (2004). Effect of $\mathrm{pH}$ and calcium level on the biochemical, textural and functional properties of reduced-fat Mozzarella cheese. International Dairy Journal, 14, 161-172. http://dx.doi.org/10.1016/S0958-6946(03)00167-5

Silva, R. C. S. N., Minim, V. P. R., Lima, L.P., Gomide, A.I., Moraes, L. E. S., \& Minim, L.A. (2012a). Optimization of the sensory acceptability of light cream cheesecurd. Ciencia Rural, 42(2), 360-366. http://dx.doi.org/10.1590/S0103-84782012000200027

Silva, R. C. S. N., Minim, V. P. R., Simiqueli, A. A., Moraes, L. E. S., Gomide, A. I., \& Minim, L. A. (2012b). Optimized Descriptive Profile: a rapid methodology for sensory description. Food Quality and Preference, 24(1), 190-200. http://dx.doi.org/10.1016/j.foodqual.2011.10.014

Silva, R. C. S. N., Minim, V. P. R., Vidigal, M. C. T. R., Silva, A. N., Simiqueli, A. A., \& Minim, L. A. (2012c). Journal of Food Research, 1(3), 204-2013. http://dx.doi.org/10.5539/jfr.v1n3p204

Silva, R. C. S. N., Minim, V. P. R., Carneiro, J. D. S., Nascimento, M., Della Lucia, S. M., \& Minim, L. A. (2013). Quantitative sensory description using the Optimized Descriptive Profile: comparison with conventional and alternative methods for evaluation of chocolate. Food Quality and Preference, 30, 169-179. http://dx.doi.org/10.1016/j.foodqual.2013.05.011

Soares, F. M., Fonseca, L. M., Martins, R. T., Machado, E. C., Pereira, Jr, F. N., \& Fonseca, C. S. P. (2002). Influência do concentrado protéico de soro na composição do requeijão em barra com teor reduzido de gordura. Arquivo Brasileiro de Medicina Veterinária e Zootecnia, 54, 1-7. http://dx.doi.org/10.1590/S0102-09352002000600014 
Udyarajan, C. U., Horne, D. S., \& Lucey, J. A. (2007). Use of time-temperature superposition to study the rheological properties of cheese during heating and cooling. International Journal of Food Science and Technology, 42, 686-698. http://dx.doi.org/10.1111/j.1365-2621.2006.01468.x

United States Department Of Agriculture. USDA. (1963). Composition of Foods Washington: USDA, p. 190.

Zalazar, C. A., Zalazar, C. S., Bernal, S., Bertola, N., Bevilacqua, A., \& Zaritzky, N. (2002). Effect of moisture level and fat replacer on physicochemical, reological and sensory properties of low fat soft cheeses. International Dairy Journal, 12 (1), 45-50. http://dx.doi.org/10.1016/S0958-6946(01)00130-3

\section{Copyrights}

Copyright for this article is retained by the author(s), with first publication rights granted to the journal.

This is an open-access article distributed under the terms and conditions of the Creative Commons Attribution license (http://creativecommons.org/licenses/by/3.0/). 